\title{
Age alone should not preclude surgery: Contemporary outcomes after aortic valve replacement in nonagenarians
}

\author{
Isaac George, MD, ${ }^{a}$ Halit Yerebakan, MD, ${ }^{a}$ Bindu Kalesan, $\mathrm{PhD},{ }^{\mathrm{a}}$ Tamim Nazif, MD, ${ }^{\mathrm{b}}$ \\ Susheel Kodali, MD, ${ }^{\mathrm{b}}$ Craig R. Smith, MD, ${ }^{\mathrm{a}}$ and Mathew R. Williams, MD ${ }^{\mathrm{a}, \mathrm{b}}$
}

Objectives: Advanced age plays a major role in surgical risk algorithms; however, the outcomes data for the very elderly are lacking. We, therefore, evaluated the outcomes after surgical aortic valve replacement (SAVR) in nonagenarians (age, $>90$ years) at our institution during an 11-year period.

\begin{abstract}
Methods: The demographics, procedural details, and in-hospital outcomes were retrospectively analyzed for 119 nonagenarians with symptomatic, severe aortic stenosis who had undergone SAVR or SAVR plus concomitant surgery from 2001 to 2012. The mean follow-up period was $915 \pm 832$ days.
\end{abstract}

\begin{abstract}
Results: The average age was $91.7 \pm 1.9$ years (range, 90-98), and the mean Society of Thoracic Surgeons score was $8.9 \pm 5.7$. The mean aortic valve gradient was $45 \pm 16 \mathrm{~mm} \mathrm{Hg}$, mean aortic valve area was $0.66 \pm 0.2 \mathrm{~cm}^{2}$, and mean ejection fraction was $49.8 \% \pm 11.8 \% ; 47 \%$ underwent isolated SAVR. The average length of stay was longer than expected; however, the rates of prolonged ventilation $(16.8 \%)$, new atrial fibrillation $(43.7 \%)$, stroke $(0.8 \%)$, and renal failure $(5.9 \%)$ were acceptable. Three patients $(2.5 \%)$ required reoperation for bleeding. Overall, the 30-day and 1-year mortality was $7.6 \%$ and $21.0 \%$, respectively. The multivariate predictors of mortality at 1 year included previous myocardial infarction (hazard ratio, 2.79; $95 \%$ confidence interval, 1.21-6.45; $P=.016$ ), obstructive lung disease (hazard ratio, 3.90; 95\% confidence interval, 1.66-9.15; $P=.025$ ), and diabetes (hazard ratio, 2.77; 95\% confidence interval, 1.08-7.07; $P=.033$ ). The observed in-hospital mortality was lower than expected (observed/expected, 0.85).
\end{abstract}

Conclusions: Excellent procedural and long-term outcomes can be achieved in nonagenarians, and age alone should not be a contraindication to SAVR in selected populations. Our sample cohort has validated the feasibility of a primary operative strategy in elderly patients with aortic stenosis and acceptable risk profiles. (J Thorac Cardiovasc Surg 2014;148:1360-9)

Supplemental material is available online.

The increasingly aging population, with its proportionally greater prevalence of aortic stenosis (AS), has made symptomatic, severe AS in the very elderly an important clinical question. The establishment of transcatheter aortic valve replacement (TAVR) has complicated the treatment algorithm for AS in the very elderly, in particular, in those

From the Divisions of Cardiothoracic Surgery ${ }^{\mathrm{a}}$ and Cardiology, ${ }^{\mathrm{b}}$ Columbia University College of Physicians and Surgeons, New York Presbyterian Hospital, New York, NY.

Disclosures: Susheel Kodali reports consulting fees from Edwards and St. Jude, and equity ownership in Thubrikar Aortic Valve Inc and VS Medtech Inc. Mathew R. Williams reports consulting fees from Edwards and Medtronic. All other authors have nothing to disclose with regard to commercial support.

Drs George and Yerebakan contributed equally to the present report.

Received for publication Sept 26, 2013; revisions received Dec 17, 2013; accepted for publication Jan 10, 2014; available ahead of print Feb 19, 2014.

Address for reprints: Isaac George, MD, Division of Cardiothoracic Surgery, Columbia University College of Physicians and Surgeons, New York Presbyterian Hospital, MHB 7GN-435, 177 Fort Washington Ave, New York, NY 10032 (E-mail: ig2006@columbia.edu).

0022-5223/\$36.00

Copyright (c) 2014 by The American Association for Thoracic Surgery

http://dx.doi.org/10.1016/j.jtcvs.2014.01.015
$>90$ year old (nonagenarians). The Placement of AoRTic TraNscathetER Valve (PARTNER) trial has shown TAVR to be an effective treatment in nonoperative patients and an equivalent treatment to surgical aortic valve replacement (SAVR) in high-risk patients with AS, with supporting data extending to 3 years. ${ }^{1}$ Thus, TAVR has been approved for commercial use in these populations. ${ }^{2}$ Surgical risk algorithms play an important role in patient risk stratification, and advanced age has been a large component of traditional surgical risk scoring systems (predicted risk of mortality Society of Thoracic Surgeons [STS] score and the logistic EuroSCORE) when evaluating elderly patients. Advanced age has often been used as rationale for pursuing medical therapy or TAVR to avoid the burden of recovery associated with SAVR. However, anecdotal surgical reports and published data from octogenarians have suggested that SAVR in selected elderly populations is not only feasible, but can also provide excellent outcomes in selected patients, ${ }^{2}$ with reported 30 -day mortality rates as low as $2.3 \%$ to $2.8 \%$ in octogenarians.

Conventional SAVR has long been considered the reference standard for the treatment of AS; however, outcomes data after SAVR from nonagenarians are lacking. The present study is the first, to the best of our knowledge, to define the surgical outcomes of patients aged $\geq 90$ years 


\author{
Abbreviations and Acronyms \\ AS $=$ aortic stenosis \\ AVR $=$ aortic valve replacement \\ BMI = body mass index \\ $\mathrm{CI}=$ confidence interval \\ $\mathrm{HR}=$ hazard ratio \\ ICU = intensive care unit \\ MI = myocardial infarction \\ SAVR $=$ surgical aortic valve replacement \\ STS = Society of Thoracic Surgeons \\ TAVR $=$ transcatheter aortic valve replacement
}

in the current era. In addition to describing the mortality and morbidity of SAVR in this population, we have evaluated the effect of additional surgical procedures on the outcomes and described the predictors of all-cause mortality. This information is critical for the future development of treatment algorithms for AS in the very elderly, which can include medical therapy, TAVR, and SAVR.

\section{METHODS}

\section{Patient Population}

From January 2001 to November 2012, 119 consecutive patients aged $\geq 90$ years had undergone SAVR with or without concomitant cardiac surgical procedures at our institution. The demographic and clinical outcome data were retrospectively collected from a medical records review. The present study met all the guidelines of the institutional review board of Columbia University.

\section{Demographics and Risk Factors}

The demographic and preoperative variables collected included age, gender, race, body mass index (BMI), and comorbid medical conditions, including low body weight (BMI $<20 \mathrm{~kg} / \mathrm{m}^{2}$ ), obesity $\left(\right.$ BMI $\left.>25 \mathrm{~kg} / \mathrm{m}^{2}\right)$, diabetes, hypertension, chronic obstructive pulmonary disease, renal failure, smoking history, severe aortic wall calcification, peripheral arterial disease, cerebrovascular disease, atrial fibrillation, and previous myocardial infarction (MI), percutaneous transluminal coronary angioplasty, or cardiac surgery (see the Appendix E1 for the full details of the definitions). The preoperative clinical status, including the Canadian Cardiovascular Society angina classification, New York Heart Association symptom class, and requirement for intra-aortic balloon pump, was also collected. Finally, the echocardiographic variables, including the preoperative left ventricular ejection fraction, and valvular pathologic features and severity, were also recorded in the database.

All surgeries were performed using a standard, median sternotomy approach, with cardiopulmonary bypass and mild systemic hypothermia $\left(30^{\circ}-34^{\circ} \mathrm{C}\right)$. Myocardial protection was achieved with either cold blood ( $1 \mathrm{~L}$ antegrade followed by repeated doses every 20 minutes; from 2001 to 2010) or del Nido solution (1 L antegrade single dose; from 2011 to 2012) cardioplegia. ${ }^{5}$

The selection of valve prosthesis type was at the discretion of the operating surgeon, with a strong preference for biologic valves in this age group, regardless of the preoperative presence of chronic atrial fibrillation or other clinical variables. All patients underwent coronary angiography and echocardiography before surgery. Coronary artery bypass grafting, additional valvular procedures, or other cardiac surgical procedures were performed for any recognized indications.
The operative details that were collected included the priority of surgery (elective, urgent, emergency), concomitant surgery performed, type and size of the valve prosthesis, cardiopulmonary bypass time, and global ischemic time. Postoperative in-hospital complications included the need for intra-aortic balloon pump or mechanical circulatory support, inotrope dependence on intensive care unit (ICU) admission, ventricular or atrial arrhythmia, need for a permanent pacemaker, respiratory failure, renal failure, sepsis or endocarditis, sternal wound infection, gastrointestinal bleeding, stroke, MI, and reoperation for bleeding as defined by the Valve Academic Research Consortium definitions. ${ }^{6}$

The primary outcomes included the length of ICU stay, the total length of hospital stay, in-hospital mortality, discharge status, and 1- and 5-year survival status. A follow-up rate of $100 \%$ for survival status was achieved using the Social Security Death Index. The discharge placement locations included home, physical rehabilitation facilities, and skilled nursing homes.

\section{Statistical Analysis}

Continuous variables are presented as the mean \pm standard deviations, and categorical data are presented as counts and percentages. All patients were included in the final analysis. Survival curves were constructed for time-to-event variables using Kaplan-Meier estimates. Survival comparisons among the groups of patients were performed using the Mantel-Haenszel log-rank test. Univariate and multivariate Cox proportional hazard regression models were used to assess the hazard ratios (HRs) and 95\% confidence intervals (CIs), comparing isolated AVR and AVR plus concomitant surgery. Landmark analyses were used according to a prespecified landmark point at 1 year (365 days), and we estimated the HRs separately for events $\leq 1$ year and from 1 to 5 years. Stratified analyses were performed according to these periods, and chi-square tests were performed to assess for an interaction between treatment effect and time. To identify the predictive factors for mortality at 30 days, 1 year, and 5 years, univariate Cox proportional hazard regression analysis was performed using clinically relevant baseline covariables (BMI $<20 \mathrm{~kg} / \mathrm{m}^{2}$, history of MI, concomitant surgery, Canadian Cardiovascular Society angina class, chronic obstructive pulmonary disease, diabetes, renal insufficiency according to the estimated glomerular filtration rate, left ventricular ejection fraction $<30 \%$, and mitral regurgitation grade $\geq 2$ ). Significant associations, defined as univariate associations with $P<.2$, were entered into a multivariate Cox proportional hazard regression model. The association of risk predictors was assessed using Wald statistics. All $P$ values were 2 sided. The data were analyzed using STATA 1212 (StataCorp LP, College Station, Tex).

\section{RESULTS \\ Baseline Characteristics}

The baseline clinical characteristics are summarized in Table 1. The SAVR volume increased each year throughout the study period (Figure 1, A). The mean patient age was $91.7 \pm 1.9$ years (range, $90-98$ ), $43.7 \%$ were women, $93.3 \%$ were white, and the mean BMI was $25.0 \pm 3.9 \mathrm{~kg} / \mathrm{m}^{2}$. Using the BMI, 17 patients were underweight $\left(<20 \mathrm{~kg} / \mathrm{m}^{2}\right)$, and $41.2 \%$ of the patients were classified as overweight $\left(\mathrm{BMI}>25 \mathrm{~kg} / \mathrm{m}^{2}\right)$. One patient had undergone previous cardiac surgery, $82.4 \%$ had a history of hypertension, $11.8 \%$ had diabetes mellitus, and $38.6 \%$ had a history of tobacco use. Also, 15 patients $(12.6 \%)$ had chronic atrial fibrillation, 21 $(17.6 \%)$ had a history of stroke, and $9(7.6 \%)$ had a 
TABLE 1. Baseline patient characteristics

\begin{tabular}{|c|c|c|c|c|}
\hline Characteristic & Overall & $\begin{array}{l}\text { Isolated } \\
\text { SAVR }\end{array}$ & $\begin{array}{c}\text { SAVR } \\
\text { plus any } \\
\text { surgery }\end{array}$ & $\begin{array}{c}P \\
\text { value }\end{array}$ \\
\hline Patients & 119 & 56 & 63 & \\
\hline Age (y) & $91.7 \pm 1.9$ & $91.5 \pm 1.7$ & $92.0 \pm 2.1$ & .853 \\
\hline Female gender & $52(43.7)$ & $28(50.0)$ & $24(38.1)$ & .193 \\
\hline \multicolumn{5}{|l|}{ Race } \\
\hline White & $111(93.3)$ & $51(91.1)$ & $60(95.2)$ & .383 \\
\hline Black & $5(4.2)$ & $4(7.1)$ & $1(1.6)$ & .149 \\
\hline Hispanic & $3(2.5)$ & $1(1.8)$ & $2(3.2)$ & .625 \\
\hline BMI $\left(\mathrm{kg} / \mathrm{m}^{2}\right)$ & $25.0 \pm 3.9$ & $25.1 \pm 3.5$ & $24.9 \pm 4.3$ & .783 \\
\hline $\mathrm{BMI}<20 \mathrm{~kg} / \mathrm{m}^{2}$ & $17(14.3)$ & $7(12.5)$ & $10(15.9)$ & .597 \\
\hline Obese $\left(\right.$ BMI $\left.>25 \mathrm{~kg} / \mathrm{m}^{2}\right)$ & $49(41.2)$ & $24(42.9)$ & $25(39.7)$ & .726 \\
\hline \multicolumn{5}{|l|}{ Cardiac risk factors } \\
\hline Tobacco use & 34 (28.6) & $15(26.8)$ & $19(30.2)$ & .684 \\
\hline Hypertension & $98(82.4)$ & $49(87.5)$ & $49(77.8)$ & .160 \\
\hline Diabetes & $14(11.8)$ & $5(8.9)$ & $9(14.3)$ & .358 \\
\hline \multicolumn{5}{|l|}{ Medical history } \\
\hline Previous cardiac surgery & $1(0.8)$ & $1(1.8)$ & $0(0.0)$ & .456 \\
\hline Previous PCI & $17(14.3)$ & $12(21.4)$ & $5(7.9)$ & .038 \\
\hline \multicolumn{5}{|l|}{ Previous MI } \\
\hline None & $94(79.0)$ & 47 (83.9) & 47 (74.6) & .210 \\
\hline Yes, $<21 \mathrm{~d}$ & $7(5.9)$ & $1(1.8)$ & $6(9.5)$ & .062 \\
\hline Yes, $>21 \mathrm{~d}$ & $18(15.1)$ & $8(14.3)$ & $10(15.9)$ & .809 \\
\hline COPD & $16(13.5)$ & $8(14.3)$ & $8(12.7)$ & .801 \\
\hline Cardiogenic shock & $0(0)$ & $0(0)$ & $0(0)$ & 1.00 \\
\hline PVD & $12(10.1)$ & $4(7.1)$ & $8(12.7)$ & .306 \\
\hline Stroke & $21(17.6)$ & $9(16.1)$ & $12(19.1)$ & .670 \\
\hline Atrial fibrillation & $51(42.9)$ & $22(39.3)$ & $29(46.0)$ & .463 \\
\hline \multicolumn{5}{|l|}{ Clinical characteristics } \\
\hline $\begin{array}{l}\text { STS risk score } \\
\text { for mortality }\end{array}$ & $8.9 \pm 5.7$ & $8.7 \pm 6.5$ & $9.1 \pm 4.8$ & .706 \\
\hline NYHA class & $2.6 \pm 0.8$ & $2.5 \pm 0.8$ & $2.7 \pm 0.8$ & .176 \\
\hline Angina (CCS 3 or 4) & $34(28.6)$ & $16(28.6)$ & $18(28.6)$ & 1.00 \\
\hline \multicolumn{5}{|l|}{ Clinical status } \\
\hline Stable & $106(89.1)$ & $53(94.6)$ & $53(84.1)$ & .059 \\
\hline Unstable & $13(10.9)$ & $3(5.4)$ & $10(15.9)$ & .059 \\
\hline Creatinine (mg/dL) & $1.31 \pm 0.7$ & $1.29 \pm 0.8$ & $1.32 \pm 0.7$ & .978 \\
\hline eGFR (mL/min) & $57.9 \pm 20.5$ & $58.3 \pm 20.5$ & $57.5 \pm 20.6$ & .978 \\
\hline \multicolumn{5}{|l|}{$\begin{array}{l}\text { Renal insufficiency } \\
\quad(\text { eGFR) }\end{array}$} \\
\hline Normal $\geq 90 \mathrm{~mL} / \mathrm{min}$ & $6(5.0)$ & $2(3.6)$ & $4(6.3)$ & .497 \\
\hline Mild $60-90 \mathrm{~mL} / \mathrm{min}$ & $52(43.7)$ & $27(48.2)$ & $25(39.7)$ & .354 \\
\hline $\begin{array}{l}\text { Moderate } 30-60 \\
\mathrm{~mL} / \mathrm{min}\end{array}$ & $52(43.7)$ & $22(39.3)$ & $30(47.6)$ & .364 \\
\hline Severe $<30 \mathrm{~mL} / \mathrm{min}$ & $9(7.6)$ & $5(8.9)$ & $4(6.3)$ & .598 \\
\hline Preoperative dialysis & $3(2.5)$ & $2(3.6)$ & $1(1.6)$ & .501 \\
\hline \multicolumn{5}{|c|}{ Echocardiographic characteristics } \\
\hline LVEF $(\%)$ & $49.8 \pm 11.8$ & $48.8 \pm 12.3$ & $50.6 \pm 11.4$ & .915 \\
\hline $\mathrm{LVEF} \leq 30 \%$ & $12(10.1)$ & $6(10.7)$ & $6(9.5)$ & .830 \\
\hline $\mathrm{LVEF}<50 \%$ & $42(35.3)$ & $22(39.3)$ & $20(31.8)$ & .397 \\
\hline \multicolumn{5}{|l|}{ Valve pathology } \\
\hline Regurgitation & $2(1.7)$ & $0(0.0)$ & $2(3.2)$ & .152 \\
\hline Stenosis & $58(48.7)$ & $25(44.6)$ & $33(52.4)$ & .398 \\
\hline Mixed & 59 (49.6) & $31(55.4)$ & $28(44.4)$ & .232 \\
\hline Peak gradient $(\mathrm{mm} \mathrm{Hg})$ & $74.9 \pm 24.5$ & $77.2 \pm 25.0$ & $72.8 \pm 24.2$ & .331 \\
\hline
\end{tabular}

TABLE 1. Continued

\begin{tabular}{|c|c|c|c|c|}
\hline Characteristic & Overall & $\begin{array}{c}\text { Isolated } \\
\text { SAVR }\end{array}$ & $\begin{array}{c}\text { SAVR } \\
\text { plus any } \\
\text { surgery }\end{array}$ & $\begin{array}{r}P \\
\text { value }\end{array}$ \\
\hline Mean gradient $(\mathrm{mm} \mathrm{Hg})$ & $45.0 \pm 16.1$ & $46.0 \pm 15.9$ & $44.0 \pm 16.4$ & .501 \\
\hline Aortic valve area $\left(\mathrm{cm}^{2}\right)$ & $0.66 \pm 0.2$ & $0.69 \pm 0.2$ & $0.64 \pm 0.2$ & .860 \\
\hline \multicolumn{5}{|l|}{ Aortic stenosis grade } \\
\hline None & $2(1.7)$ & $0(0.0)$ & $2(3.2)$ & .152 \\
\hline Moderate & $29(24.4)$ & $15(26.8)$ & $14(22.2)$ & .564 \\
\hline Severe & $88(74.0)$ & $39(69.6)$ & $49(77.8)$ & .314 \\
\hline \multicolumn{5}{|l|}{ Aortic insufficiency grade } \\
\hline None & $55(46.2)$ & $23(41.1)$ & $32(50.8)$ & .306 \\
\hline Mild & $39(32.8)$ & $19(33.9)$ & $20(31.8)$ & .809 \\
\hline Moderate & $14(11.8)$ & $7(12.5)$ & $7(11.1)$ & .815 \\
\hline Severe & $11(9.2)$ & $7(12.5)$ & $4(6.4)$ & .262 \\
\hline \multicolumn{5}{|l|}{ Mitral stenosis grade } \\
\hline None & $116(97.5)$ & $55(98.2)$ & $61(96.8)$ & .625 \\
\hline Mild & $1(0.8)$ & $0(0.0)$ & $1(1.6)$ & .315 \\
\hline Moderate & $2(1.7)$ & $1(1.8)$ & $1(1.6)$ & .934 \\
\hline \multicolumn{5}{|l|}{ Mitral regurgitation grade } \\
\hline None & $43(36.1)$ & $24(42.9)$ & $19(30.2)$ & .152 \\
\hline Trace & $38(31.9)$ & $15(26.8)$ & $23(36.5)$ & .256 \\
\hline Mild & $22(18.5)$ & $13(23.2)$ & $9(14.3)$ & .218 \\
\hline Moderate & $14(11.8)$ & $4(7.1)$ & $10(15.9)$ & .129 \\
\hline Severe & $2(1.7)$ & $0(0.0)$ & $2(3.2)$ & .152 \\
\hline \multicolumn{5}{|c|}{ Tricuspid regurgitation grade } \\
\hline None & $75(63.0)$ & $36(64.3)$ & $39(61.9)$ & .788 \\
\hline Trace & $25(21.0)$ & $11(19.6)$ & $14(22.2)$ & .729 \\
\hline Mild & $12(10.1)$ & $7(12.5)$ & $5(7.9)$ & .413 \\
\hline Moderate & $6(5.0)$ & $2(3.6)$ & $4(6.4)$ & .484 \\
\hline Severe & $1(0.8)$ & $0(0.0)$ & $1(1.6)$ & .315 \\
\hline
\end{tabular}

Data presented as mean \pm standard deviation or $\mathrm{n}(\%)$. SAVR, Surgical aortic valve replacement; $B M I$, body mass index; $P C I$, percutaneous coronary intervention; $M I$, myocardial infarction; COPD, chronic obstructive pulmonary disorder; $P V D$, peripheral vascular disease; STS, Society of Thoracic Surgeons; NYHA, New York Heart Association; CCS, Canadian Cardiovascular Society; eGFR, estimated glomerular filtration rate; $L V E F$, left ventricular ejection fraction.

severe reduction in the estimated glomerular filtration rate, as calculated by the Modification of Diet in Renal Disease study equation, with an estimated glomerular filtration rate $<30 \mathrm{~mL} / \mathrm{min}$. Only 3 patients $(2.5 \%)$ had been treated with hemodialysis preoperatively (Table 1 ). The mean STS risk of mortality score for all patients was $8.9 \% \pm 5.7 \%$ for all patients, $8.7 \% \pm 6.5 \%$ for those who underwent isolated AVR, and 9.1\% $\pm 4.8 \%$ for those who underwent SAVR plus other surgery $(P=.706)$.

The most common indication for surgery was isolated severe AS $(48.7 \%)$. The patients with AS had a mean atrioventricular gradient of $45 \pm 16 \mathrm{~mm} \mathrm{Hg}$ and a calculated valve area of $0.66 \pm 0.2 \mathrm{~cm}^{2}$. Angina pectoris was present in $28.6 \%$ of all patients, and $21 \%$ had experienced MI before hospital presentation. The mean New York Heart Association class was $2.6 \pm 0.8$ for all patients, $2.5 \pm 0.8$ for isolated AVR, and $2.7 \pm 0.8$ for SAVR plus other surgery $(P=.176)$. 

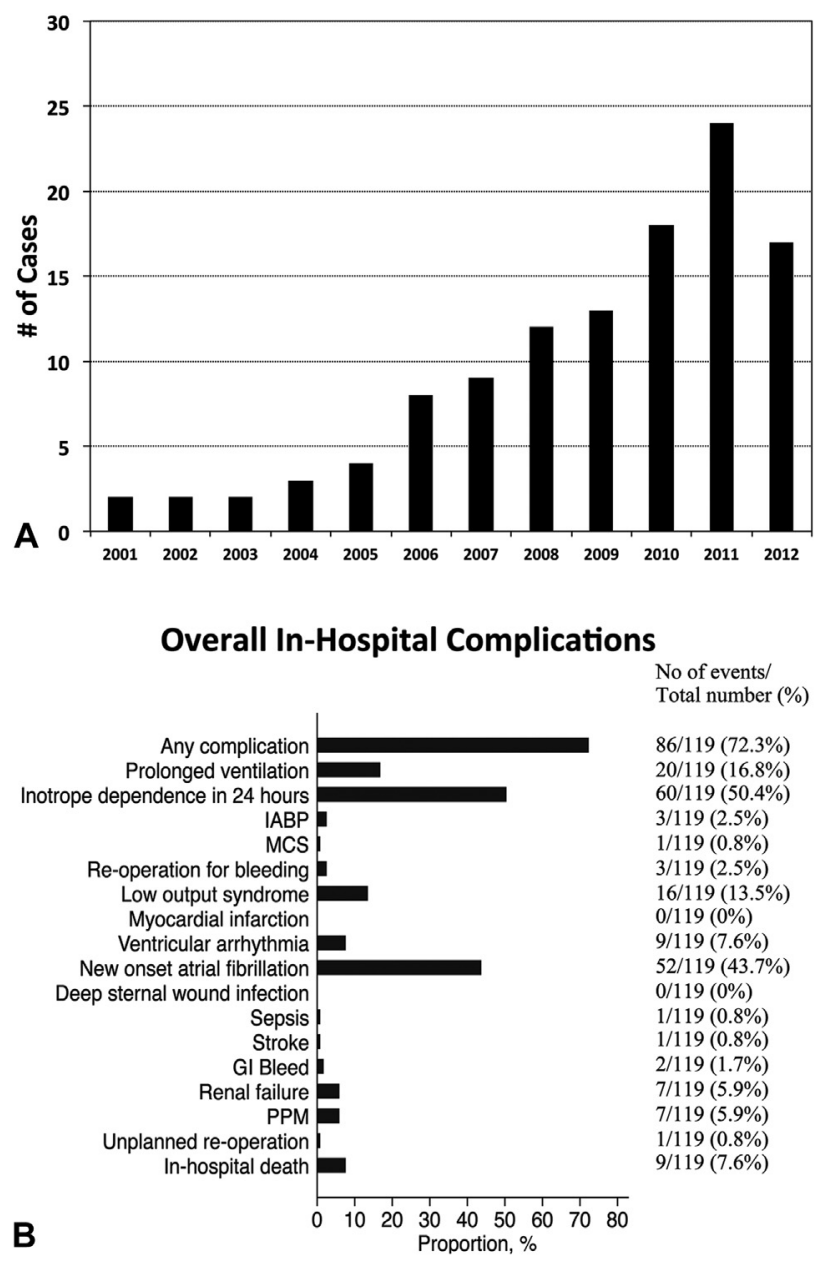

FIGURE 1. A, Case volume per year. B, Overall in-hospital complications. C, in-hospital complications stratified by type of surgery. AVR, Aortic valve replacement; $I A B P$, intra-aortic balloon pump; $M C S$, mechanical circulatory support.

\section{Operative Details}

Surgery was considered urgent in $25.2 \%$ of the patients, and $74.8 \%$ of the procedures were performed electively. Isolated AVR was performed in $47.1 \%$ of patients, concomitant coronary artery bypass grafting was performed in $39.5 \%$ of patients, and $13.4 \%$ had other concomitant cardiac procedures (mitral valve replacement, mitral valve repair, aortic root replacement, and tricuspid valve repair). Biologic prostheses were placed in the vast majority of patients $(99.2 \%)$, and $95.8 \%$ of the valves used were $\geq 21 \mathrm{~mm}$. No patient prosthesis mismatch was noted (indexed effective orifice area $<0.85 \mathrm{~cm}^{2} / \mathrm{m}^{2}$ ) in any patient. The mean cardiopulmonary bypass time was $109.0 \pm 42.6$ minutes, and the mean aortic crossclamp time was $79.1 \pm 32.4$ minutes (Table 2).

\section{Perioperative Events}

The perioperative complications are outlined in Figure 1, $B$. Inotropic support was required for the first 24 hours in $50.4 \%$ of the patients. An intra-aortic balloon pump was inserted in 3 patients $(2.5 \%)$, and 1 patient required mechanic circulatory support. Low cardiac output syndrome was observed in 16 patients $(13.5 \%)$. Mechanical ventilation was required for $>24$ hours in 20 patients $(16.8 \%)$. Renal dysfunction, defined as an increase in the serum creatinine level to $\geq 2.0 \mathrm{~g} / \mathrm{dL}$, occurred in 7 patients $(5.9 \%)$. Permanent stroke was observed in 1 patient $(0.8 \%)$. New-onset atrial fibrillation was seen in only 1 patient, although 52 of 119 patients $(43.7 \%)$ were in atrial fibrillation postoperatively owing to its relative high preoperative incidence; 7 patients $(5.9 \%)$ required a permanent pacemaker. Most $(86 \%)$ of the patients in atrial fibrillation were treated with systemic anticoagulation, and patients in sinus rhythm were maintained with daily aspirin $(81 \mathrm{mg})$. Three patients $(2.5 \%)$ required reoperation for bleeding (defined as $>1 \mathrm{~L}$ within 8 hours or a rate of $\geq 200 \mathrm{~mL} / \mathrm{h}$ for 3 hours). In all 3 patients, the total bleeding volume was $<1 \mathrm{~L}$, and no surgical bleeding was found. The addition of concomitant surgery to SAVR significantly increased the rates of prolonged ventilation, inotrope dependence at 24 hours, and low cardiac output syndrome (Figure 1, C). 


\section{In-Hospital Complications By Type of Surgery}

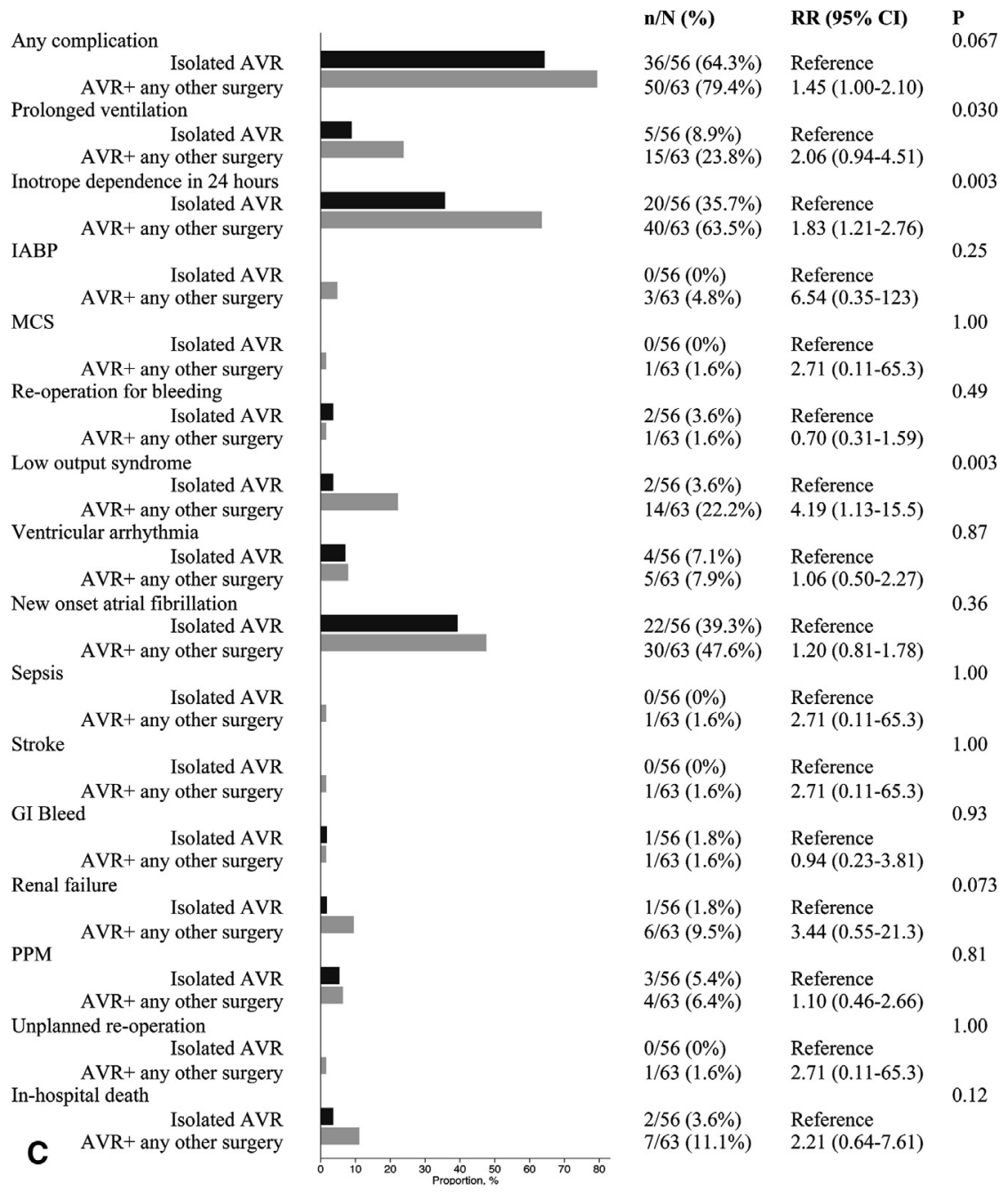

FIGURE 1. (continued).

\section{Clinical Outcomes}

The mean postoperative length of stay in the ICU for the overall cohort was $10.9 \pm 11.4$ days and was significantly prolonged by the performance of concomitant surgery (isolated AVR vs AVR with concomitant surgery, $8.3 \pm 8.4$ vs $13.2 \pm 13.3$ days; $P=.019$ ). The mean overall postoperative hospital length of stay was $16.5 \pm 11.7$ days overall and was also significantly prolonged with concomitant surgery (isolated AVR vs AVR with concomitant surgery, $13.9 \pm 9.1$ vs $18.7 \pm 13.2$ days; $P=.024)$. The overall in-hospital mortality (death before discharge) was $7.6 \%$ (9 of 119) (Table 2).

The discharge to home, skilled nursing home, and acute physical rehabilitation care facility rate was $26.1 \%$, $31.1 \%$, and $35.3 \%$, respectively (Table 2). The mean follow-up was $30.1 \pm 27.3$ months. The 5-year Kaplan Meier curves of the overall mortality and a landmark analysis at 12 months is presented in Figure 2. The overall 30-day, 1-year, and 5-year mortality rate was 7.6\%, 21.0\%, and $32.8 \%$, respectively. The late mortality for the group of isolated AVR was $16.1 \%$ and $26.8 \%$ at 1 and 5 years (Figure 2, C). The 1- and 5-year mortality for the patients who underwent AVR with concomitant surgery was $25.4 \%$ and $38.1 \%$, respectively (Figure 2, D). Although no difference was found in mortality between the 2 groups in the landmark analysis at 12 months, an overall trend was seen toward a significant difference by 5 years (HR, 1.78; 95\% CI, 0.93-3.41; log-rank, $P=.077$ ).

The influence of the TAVR era was evaluated by stratifying the patients into 2 groups: pre-TAVR (before 2007) and post-TAVR (after 2007). Before 2007 and the initiation of TAVR, 21 SAVRs in nonagenarians were performed compared with 98 SAVRs in the post-TAVR era. The average patient age $(91.3 \pm 1.0$ vs $91.0 \pm 1.9$ years $)$, 
TABLE 2. Procedural data

\begin{tabular}{|c|c|c|c|c|}
\hline Variable & Overall & $\begin{array}{c}\text { Isolated } \\
\text { SAVR }\end{array}$ & $\begin{array}{c}\text { SAVR } \\
\text { plus other }\end{array}$ & $\begin{array}{c}P \\
\text { value } \\
\end{array}$ \\
\hline Patients & 119 & 56 & 63 & \\
\hline \multicolumn{5}{|l|}{ Concomitant surgery status } \\
\hline Isolated AVR & $56(47.1)$ & $56(100)$ & & \\
\hline SAVR plus CABG & $47(39.5)$ & & 47 (74.6) & \\
\hline SAVR plus MVR & $10(8.4)$ & & $10(15.8)$ & \\
\hline SAVR plus other & $6(5.0)$ & & $6(9.6)$ & \\
\hline Operative priority, urgent & $30(25.2)$ & $15(26.8)$ & $15(23.8)$ & .710 \\
\hline \multicolumn{5}{|l|}{ Prosthesis brand } \\
\hline $3 \mathrm{~F}$ & $2(1.7)$ & $2(3.6)$ & $0(0.0)$ & .152 \\
\hline Edwards & $72(61.0)$ & $38(67.9)$ & $34(54.8)$ & .144 \\
\hline Homograft & $1(0.8)$ & $1(1.8)$ & $0(0.0)$ & .315 \\
\hline Hancock II & $6(5.1)$ & $1(1.8)$ & $5(8.1)$ & .109 \\
\hline Medtronic & 35 (29.7) & $14(25.0)$ & $21(33.9)$ & .290 \\
\hline Sorin & $2(1.7)$ & $0(0.0)$ & $2(3.2)$ & .157 \\
\hline \multicolumn{5}{|l|}{ Prosthesis type } \\
\hline Homograft & $1(0.8)$ & $1(1.8)$ & $0(0.0)$ & .315 \\
\hline Medtronic Mosaic & $35(29.4)$ & $14(25.0)$ & $21(33.3)$ & .321 \\
\hline Edwards Pericardial & $82(68.9)$ & $41(73.2)$ & $41(65.1)$ & .341 \\
\hline Repair & $1(0.8)$ & $0(0.0)$ & $1(1.6)$ & .315 \\
\hline \multicolumn{5}{|l|}{ Size (n) } \\
\hline $19 \mathrm{~mm}$ & $5(4.2)$ & $4(7.1)$ & $1(1.6)$ & .150 \\
\hline $21 \mathrm{~mm}$ & $36(30.5)$ & $20(35.7)$ & $16(25.8)$ & .247 \\
\hline $22 \mathrm{~mm}$ & $1(0.8)$ & $1(1.8)$ & $0(0.0)$ & .315 \\
\hline $23 \mathrm{~mm}$ & $47(39.8)$ & $22(39.3)$ & $25(40.3)$ & .913 \\
\hline $25 \mathrm{~mm}$ & $18(15.3)$ & $4(7.1)$ & $14(22.6)$ & .015 \\
\hline $27 \mathrm{~mm}$ & $9(7.6)$ & $4(7.1)$ & $5(8.1)$ & .839 \\
\hline $29 \mathrm{~mm}$ & $2(1.7)$ & $1(1.8)$ & $1(1.6)$ & .934 \\
\hline Indexed EOA $\left(\mathrm{cm}^{2} / \mathrm{m}^{2}\right)$ & $2.1 \pm 0.4$ & $2.0 \pm 0.3$ & $2.1 \pm 0.3$ & .921 \\
\hline $\begin{array}{l}\text { Severe aortic wall } \\
\text { calcification }\end{array}$ & $14(11.8)$ & $5(8.9)$ & $9(14.3)$ & .358 \\
\hline Crossclamp time (min) & $79.1 \pm 32.4$ & $61.3 \pm 17.4$ & $95.5 \pm 34.5$ & $<.001$ \\
\hline CPB time (min) & $109.0 \pm 42.6$ & $87.5 \pm 24.0$ & $128.7 \pm 46.3$ & $<.001$ \\
\hline IMA usage & $43(36.1)$ & & $43(62.8)$ & \\
\hline $\begin{array}{l}\text { Average number of bypass } \\
\text { grafts in patients } \\
\text { undergoing CABG }\end{array}$ & & & $1.76 \pm 0.85$ & \\
\hline \multicolumn{5}{|l|}{ Cardioplegia method } \\
\hline Antegrade & $13(10.9)$ & $6(10.7)$ & $7(11.1)$ & .945 \\
\hline $\begin{array}{l}\text { Antegrade and } \\
\text { retrograde }\end{array}$ & $106(89.1)$ & $50(89.3)$ & $56(88.9)$ & .945 \\
\hline Duration of ICU stay (d) & $10.9 \pm 11.4$ & $8.3 \pm 8.4$ & $13.2 \pm 13.3$ & .019 \\
\hline $\begin{array}{l}\text { Duration of hospital } \\
\text { stay (d) }\end{array}$ & $16.5 \pm 11.7$ & $13.9 \pm 9.1$ & $18.7 \pm 13.2$ & .024 \\
\hline \multicolumn{5}{|l|}{ Discharge location } \\
\hline Home & $31(26.1)$ & $21(37.5)$ & $11(17.5)$ & .014 \\
\hline Nursing home & $37(31.1)$ & $16(28.6)$ & $21(33.3)$ & .582 \\
\hline Physical rehabilitation & $42(35.3)$ & $16(28.6)$ & $26(41.3)$ & .146 \\
\hline In-hospital mortality & $9(7.6)$ & $3(5.4)$ & $5(7.9)$ & .586 \\
\hline
\end{tabular}

Data presented as mean \pm standard deviation or $\mathrm{n}(\%)$. SAVR, Surgical aortic valve replacement; $A V R$, aortic valve replacement; $C A B G$, coronary artery bypass grafting; $E O A$, effective orifice area; $C P B$, cardiopulmonary bypass; $I M A$, internal mammary artery; $I C U$, intensive care unit; $M V R$, mitral valve replacement.

STS score $(8.4 \pm 4.2$ vs $9.0 \pm 6.1)$, ICU length of stay $(11.7 \pm 17.9$ vs $7.1 \pm 9.3$ days), and hospital length of stay $(14.05 \pm 12.2$ vs $12.9 \pm 9.2$ days $)$ were equivalent for the pre-TAVR and post-TAVR eras (all $P=\mathrm{NS}$ ). The mortality at 30 days and 5 years was similar in both eras (30 days, $4.8 \% \pm 3.4 \%$ vs $7.1 \% \pm 4.5 \%$ pre- vs postTAVR era; 5 years, $29.1 \% \pm 10.6 \%$ vs $44.4 \% \pm 7.4 \%$, pre- vs post-TAVR era; log-rank, $P=.559$ ).

\section{Predictors of 30-Day, 1-Year, and 5-Year Mortality}

The mean duration of follow-up was $915 \pm 832$ days, with $100 \%$ complete follow-up. A low BMI at baseline, diabetes mellitus, and undergoing a concomitant procedure were associated with perioperative complications on univariate analysis but were not significant independent predictors on multivariate logistic regression modeling (Table 3). On multivariate analysis, a history of diabetes mellitus was the only significant independent risk factor for 30-day mortality (HR, 5.24; 95\% CI, 1.12-24.5; $P=.035$; Table 3). However, a history of MI (HR, 2.30; 95\% CI, 1.09-4.83), chronic obstructive pulmonary disease (HR, 2.52; 95\% CI, 1.09-5.83), and diabetes (HR, 2.60; 95\% CI, 1.02-6.61) were identified as independent risk factors for 1- and 5-year mortality (Table 3).

\section{DISCUSSION}

Recent population studies have demonstrated that almost $10 \%$ of octogenarians have severe AS and have suggested a prevalence of $10 \%$ to $15 \%$ in nonagenarians. ${ }^{7}$ The growing population of very elderly patients, including nonagenarians, in Western society poses distinct challenges to the evaluating clinician, who must weigh the indications for intervention, quality of life, recovery and morbidity, timing of the intervention, and, ultimately, the optimal treatment for this complex group of patients. The historic reluctance to operate on nonagenarians could have contributed to the reported $30 \%$ of patients with severe AS who have not undergone valve replacement. ${ }^{8,9}$ The perceived risk of surgery in nonagenarians has been supported by high mortality rates from a number of small case series, which have been limited by small sample sizes, a lack of follow-up after hospital discharge, and minimal data reported specifically related to the SAVR procedure. In the present study, we have reported the largest-to-date contemporary surgical experience of AVR with and without concomitant cardiac surgical procedures from a center with extensive experience in SAVR and TAVR. Our primary findings were that the observed mortality of $7.6 \%$ was lower than the mortality predicted using standard risk scoring algorithms and previously reported mortality; a prolonged length of hospital and ICU stay can be required in this patient population; concomitant surgical procedures negatively affected the short- and long-term outcomes; and a history of diabetes, chronic obstructive pulmonary disease, and previous MI are independent risk factors for 1- and 5-year mortality. From these results, we believe it 
Landmark All-Cause Mortality at 1 year

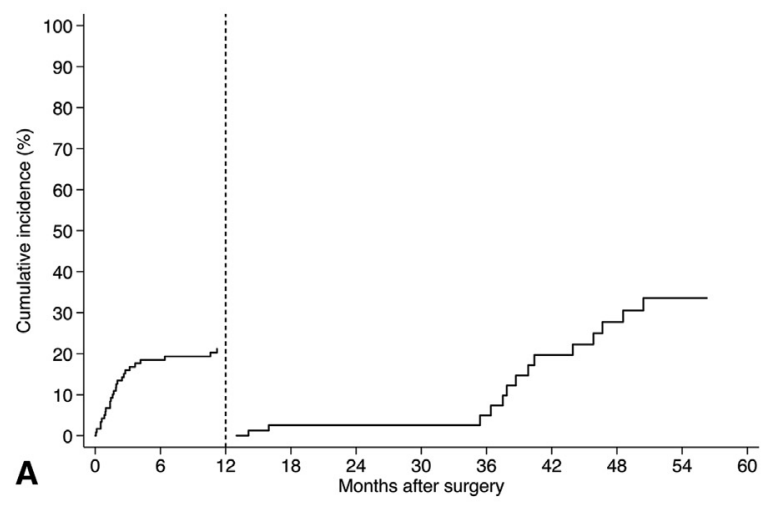

Landmark All-Cause Mortality by Surgery Type at 1 year

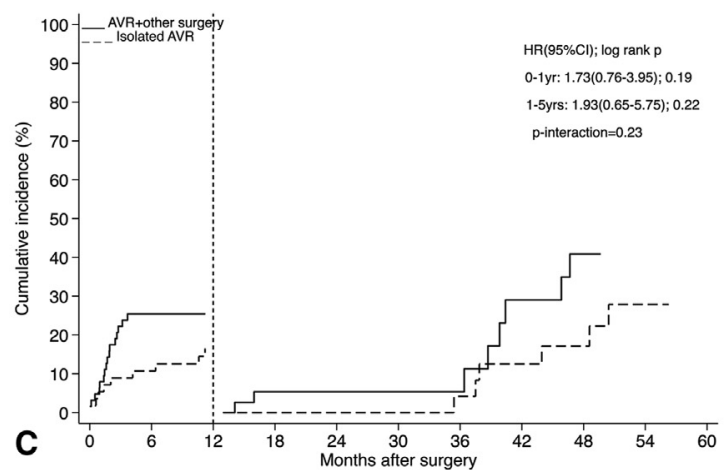

Overall All-Cause Mortality at 5 Years

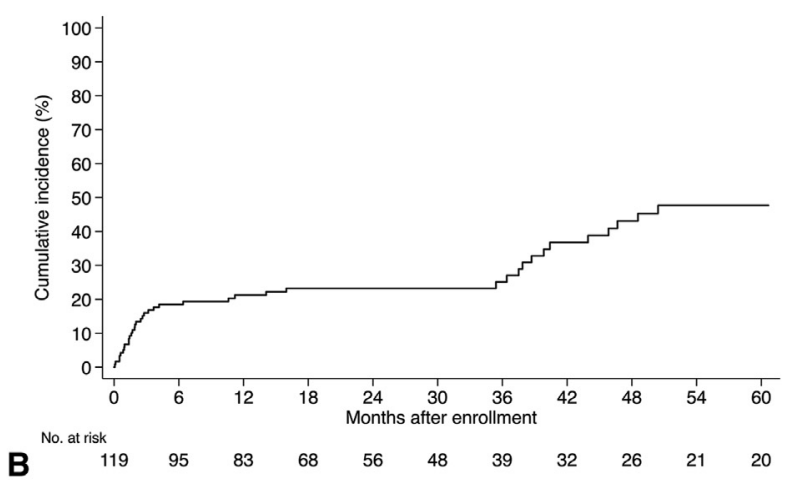

Overall All-Cause Mortality by Surgery Type at 5 years

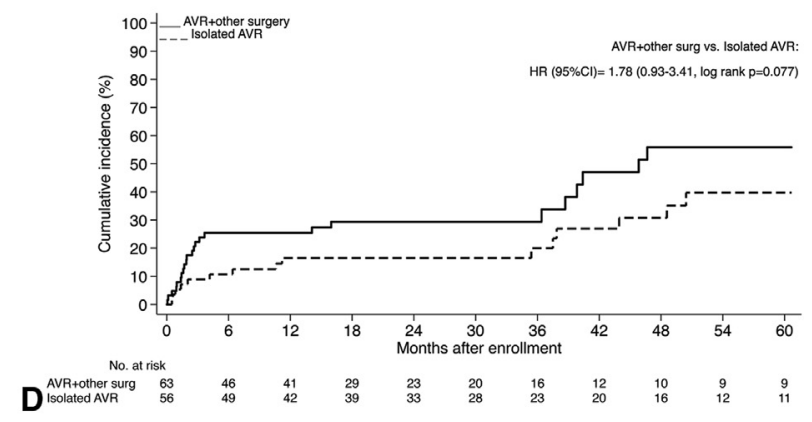

FIGURE 2. A, Landmark all-cause mortality at 1 year. B, Overall all-cause mortality at 5 years. C, Landmark all-cause mortality at 1 year stratified by surgery type. D, Overall all-cause mortality at 5 years stratified by surgery type. AVR, Aortic valve replacement.

is reasonable to consider SAVR in the therapeutic algorithm for selected nonagenarians despite their advanced age.

The most recent report of SAVR in nonagenarians retrospectively evaluated 30 patients with severe AS and a mean age of 91.5 years treated within the previous 16 years in Germany. ${ }^{10}$ In that small series, the in-hospital mortality was $13 \%$, and the surgical procedural times were prolonged (mean, $77 \pm 23$ minutes, 12 of 30 patients with operative times $>80$ minutes). Heart valve replacement was similarly examined in 35 nonagenarians from the late 1990s in the United Kingdom, revealing a $17 \%$ mortality rate and an average length of hospital stay of 18 days. ${ }^{11}$ The preoperative predicted risk scores were not provided in either study. The largest series of cardiac surgery (both valvular and nonvalvular) in nonagenarians by Speziale and colleagues ${ }^{12}$ included 127 patients with a mean logistic EuroSCORE of 21.3 and demonstrated a 30-day mortality of $13.4 \%$.

Several factors can account for the lower observed mortality ( $7.6 \%$ overall, $3.4 \%$ for isolated SAVR) in our study. First, our results reflected a learning curve with accumulating experience with an increasing case volume over time (Figure 1). With this experience, the preoperative evaluation and postoperative care of extremely elderly patients has been improved and also facilitated by our TAVR experience. Routine preoperative testing included echocardiography and coronary catheterization, just as was performed in the pre-TAVR era before 2007. It now also includes pulmonary function testing, carotid ultrasonography, and, often, computed tomography of the chest to assess for aortic calcification. ICU algorithms, ventilator strategies, closer attention to tissue integrity and avoidance of bleeding, and strong postoperative rehabilitation programs for elderly patients have all advanced during the past decade. The large majority of our operations were performed under elective conditions and not in an urgent or emergency setting, which has been shown to impart a significant hazard for death. ${ }^{12}$ Most importantly, the level of comorbid conditions in our cohort of patients was relatively low, and the predominant factor in the high STS score of the group was advanced age. Physiologic age, which has been suggested by others, ${ }^{13,14}$ might be a more important survival predictor than risk scores alone, and frailty testing has been emerging as an important part of the surgical evaluation of elderly patients. 
TABLE 3. Predictors of all-cause mortality

\begin{tabular}{|c|c|c|c|c|c|c|}
\hline Mortality & Dead & Alive & Crude HR $(95 \%$ CI $)$ & $P$ value & Multivariate HR $(95 \%$ CI $)$ & $P$ value \\
\hline \multicolumn{7}{|l|}{ At $30 \mathrm{~d}$} \\
\hline $\mathrm{BMI} \leq 20 \mathrm{~kg} / \mathrm{m}^{2}$ & $2(25.0)$ & $15(13.5)$ & $1.62(0.31-8.43)$ & .57 & & \\
\hline Previous MI & $3(37.5)$ & $22(19.8)$ & $2.73(0.63-11.9)$ & .18 & $1.67(0.34-8.15)$ & .53 \\
\hline SAVR with concomitant surgery & $5(62.5)$ & $58(52.3)$ & $1.73(0.41-7.31)$ & .46 & & \\
\hline Angina (CCS 3 or 4$)$ & $4(50.0)$ & $30(27.0)$ & $2.88(0.68-12.2)$ & .15 & $1.67(0.34-8.12)$ & .52 \\
\hline COPD & $3(37.5)$ & $13(11.8)$ & $4.92(1.15-21.1)$ & .032 & $3.30(0.68-15.9)$ & .14 \\
\hline Diabetes & $3(37.5)$ & $11(9.9)$ & $5.74(1.33-24.8)$ & .019 & $5.24(1.12-24.5)$ & .035 \\
\hline Renal insufficiency, eGFR $<30 \mathrm{~mL} / \mathrm{min}$ & $2(25.0)$ & $8(7.2)$ & $3.75(0.75-18.7)$ & .11 & $3.95(0.68-22.9)$ & .13 \\
\hline $\mathrm{LVEF}<30 \%$ & $1(12.5)$ & $11(9.9)$ & $1.33(0.15-11.0)$ & .80 & & \\
\hline MR grade $\geq 2$ & $4(50.0)$ & $34(30.6)$ & $2.23(0.52-9.65)$ & .28 & & \\
\hline \multicolumn{7}{|l|}{ At $1 \mathrm{y}$} \\
\hline $\mathrm{BMI} \leq 20 \mathrm{~kg} / \mathrm{m}^{2}$ & $4(16.0)$ & $13(13.8)$ & $1.28(0.43-3.85)$ & .66 & & \\
\hline Previous MI & $10(40.0)$ & $15(15.9)$ & $3.12(1.37-7.11)$ & .007 & $2.79(1.21-6.45)$ & .016 \\
\hline SAVR with concomitant surgery & $16(64.0)$ & $47(50.0)$ & $1.68(0.74-3.87)$ & .22 & & \\
\hline Angina (CCS 3 or 4$)$ & $10(40.0)$ & $24(25.5)$ & $1.83(0.78-4.27)$ & .16 & $1.53(0.63-3.71)$ & .35 \\
\hline COPD & $8(32.0)$ & $8(8.60)$ & $3.90(1.66-9.15)$ & .002 & $2.76(1.14-6.70)$ & .025 \\
\hline Diabetes & $6(24.0)$ & $8(8.5)$ & $3.29(1.26-8.58)$ & .015 & $2.77(1.08-7.07)$ & .033 \\
\hline Renal insufficiency, eGFR $<30 \mathrm{~mL} / \mathrm{min}$ & $3(12.0)$ & $7(7.5)$ & $1.69(0.50-5.66)$ & .40 & & \\
\hline $\mathrm{LVEF}<30 \%$ & $3(12.0)$ & $9(9.6)$ & $1.29(0.38-4.37)$ & .69 & & \\
\hline MR grade $\geq 2$ & $9(36.0)$ & $29(30.9)$ & $1.25(0.52-3.02)$ & .61 & & \\
\hline \multicolumn{7}{|l|}{ At $5 \mathrm{y}$} \\
\hline $\mathrm{BMI} \leq 20 \mathrm{~kg} / \mathrm{m}^{2}$ & $6(15.4)$ & $11(13.7)$ & $1.36(0.55-3.33)$ & .50 & & \\
\hline Previous MI & $12(30.8)$ & $13(16.3)$ & $2.59(1.28-5.24)$ & .008 & $2.30(1.09-4.83)$ & .028 \\
\hline SAVR with concomitant surgery & $24(61.5)$ & $39(48.7)$ & $1.69(0.87-3.31)$ & .12 & $1.77(0.90-3.46)$ & .096 \\
\hline Angina (CCS 3 or 4$)$ & $15(38.5)$ & $19(23.7)$ & $1.49(0.75-2.95)$ & .25 & & \\
\hline COPD & $8(20.5)$ & $8(10.0)$ & $2.62(1.18-5.76)$ & .017 & $2.52(1.09-5.83)$ & .031 \\
\hline Diabetes & $6(15.4)$ & $8(10.0)$ & $2.16(0.87-5.40)$ & .099 & $2.60(1.02-6.61)$ & .045 \\
\hline Renal insufficiency, eGFR $<30 \mathrm{~mL} / \mathrm{min}$ & $4(10.3)$ & $6(7.5)$ & $1.37(0.48-3.87)$ & .56 & & \\
\hline $\mathrm{LVEF}<30 \%$ & $4(10.3)$ & $8(10.0)$ & $0.94(0.33-2.70)$ & .92 & & \\
\hline MR grade $\geq 2$ & $18(46.1)$ & $20(25.0)$ & $1.79(0.92-3.48)$ & .084 & $2.02(0.99-4.12)$ & .052 \\
\hline
\end{tabular}

Data presented as n (\%). Both crude and multivariate HRs were adjusted for age and gender. $H R$, Hazard ratio; $C I$, confidence interval; $B M I$, body mass index; $M I$, myocardial infarction; SAVR, surgical aortic valve replacement; $C C S$, Canadian Cardiovascular Society; COPD, chronic obstructive pulmonary disease; $e G F R$, estimated glomerular filtration rate; $L V E F$, left ventricular ejection fraction; $M R$, mitral regurgitation.

Another important consideration in the surgical evaluation is the potential for rehabilitation and the length of recovery. The length of ICU stay was slightly extended (mean, 10.9 days) in our cohort, but the overall length of stay (mean, 16.5 days) was acceptable, particularly compared with other data from nonagenarians undergoing cardiac surgery (mean ICU stay, 10.2 days; mean hospital stay, 29.2 days). ${ }^{12}$ Additionally, the overall length of stay in our cohort compared well with the mean length of stay of 17.6 days reported by Easo and colleagues ${ }^{15}$ and 19.8 days reported by Bacchetta and colleagues. ${ }^{16}$ The extended length of ICU stay did not result from ventilator dependence or cardiac dysfunction (Figure 1, $B$ and $C$ ) but might, in part, be attributed to the time required for careful optimization of volume status, renal function, and pain control. These parameters pose challenges in patients with advanced age secondary to the impaired metabolism of medications, variable response to narcotics, and delirium in the postoperative period. Nonetheless, the recovery time after transfer to the floor was expedient and demonstrated the capacity of functional patients to participate in rehabilitation and physical therapy. More than $70 \%$ of our patients were discharged in a functional state to their home or a rehabilitation facility. Prolonged ventilation and low cardiac output syndromes, both complications that are worsened with more extensive surgery, must be considered before undertaking surgery and might result from the primary pathologic features of the disease process of ischemia and AS with compromised ventricular function, rather than isolated AS alone, in which the ventricular function has generally been preserved.

The present study results have provided not only a reference standard for outcomes, but also insight into the decision-making algorithms for the appropriateness of SAVR versus TAVR. A number of positive findings after SAVR should be highlighted. First, the rates of bleeding $(2.5 \%)$, myocardial infarction $(0 \%)$, and stroke $(0.8 \%)$ were remarkably low. Second, despite the high rate of moderate preoperative renal dysfunction, the incidence of 
postoperative renal failure was also low $(5.9 \%)$. Finally, the rate of sepsis was negligible. However, SAVR and TAVR in nonagenarians has not been directly compared in published studies, and comparisons of nonmatched case series must be made cautiously. Although TAVR has been thought facilitate discharge and/or lower the morbidity of aortic valve intervention, the 2 published reports of TAVR outcomes in this age group might dispute this notion. In a series of 26 nonagenarians (mean age, 91.6 years; mean STS score, 13.4) who had undergone TAVR (24 transfemoral approach, 2 transthoracic), the 30-day mortality was high $(15 \%)$, and complications, such as stroke or transient ischemic attack $(15 \%)$, acute kidney injury $(15 \%)$, major vascular complications $(15 \%)$, and major bleeding $(31 \%)$ were common. ${ }^{17}$ However, it is important to note that these patients represented a much sicker population than our study group. Similarly, in 11 nonagenarians with severe AS treated with the Medtronic CoreValve transcatheter heart valve system (Medtronic, Inc, Minneapolis, Minn), the mortality was $27 \%$ at 30 days, similar to the predicted mortality of $25.3 \%$ using STS scoring. ${ }^{18}$ In both studies, the prohibitive surgical risk precluded surgery, and an investigation into the outcomes after TAVR in lower risk nonagenarians is warranted. Nonetheless, a primary surgical approach to nonagenarians with severe AS appears to be a rational, safe, and logical treatment choice if age is the primary determinant of risk; an operative mortality rate of $3 \%$ to $8 \%$ can be expected, such as was shown in our series, and a strong consideration should be made for patients requiring isolated SAVR, given its demonstrated low risk of mortality.

The limitations inherent to a retrospective analysis were present in our study. The present report has provided a full analysis of all patients undergoing SAVR at our institution. However, we could not report on those patients who were evaluated but not offered surgery. Ideally, a comparison of the present data with data from patients with similar risk but who had undergone TAVR would be informative. However, at the writing of our report, the number of operable high-risk TAVR patients $>90$ year old (and not inoperable) were too few to analyze in a meaningful fashion. Such an analysis might be possible after completion of the current intermediate-risk TAVR trials. Finally, an important variable missing from our data set was a quantitative measurement of frailty, a characteristic more recently defined as the frailty index to allow clinicians to assess a patient's strength, independence, and potential for recovery after SAVR or TAVR. ${ }^{19}$ This assessment has only been performed recently in our high-risk surgical population. We strongly advocate routine frailty testing (composite score of gait speed, grip strength, serum albumin, and activities of daily living) in high-risk elderly patients, because these metrics have been shown to be predictive of mortality at 1 year after TAVR and could also have a role in the surgical assessment.

\section{CONCLUSIONS}

The role of surgical treatment of severe AS in nonagenarians will become an increasingly relevant issue as the population continues to age, as surgical techniques and care become more refined, and as the indications for TAVR expand. The present study has provided evidence to support a primary surgical approach for select nonagenarians with isolated or combined valve and coronary disease, if other major comorbidities are absent. Extreme caution should be taken in the selection of patients undergoing SAVR with advanced risk determined by the presence of severe comorbidities other than age, and, although the overall complications were acceptable low, in-hospital recovery could be prolonged in this patient population.

\section{References}

1. Kodali SK, Williams MR, Smith CR, Svensson LG, Webb JG, Makkar RR, et al Two-year outcomes after transcatheter or surgical aortic-valve replacement N Engl J Med. 2012;366:1686-95.

2. Shan L, Saxena A, McMahon R, Wilson A, Newcomb A. A systematic review on the quality of life benefits after aortic valve replacement in the elderly J Thorac Cardiovasc Surg. 2013;145:1173-89.

3. Saxena A, Poh CL, Dinh DT, Reid CM, Smith JA, Shardey GC, et al. Early and late outcomes after isolated aortic valve replacement in octogenarians: an Australasian Society of Cardiac and Thoracic Surgeons Cardiac Surgery Database study. Eur J Cardiothorac Surg. 2012;41:63-8.

4. Iturra SA, Suri RM, Greason KL, Stulak JM, Burkhart HM, Dearani JA, et al. Outcomes of surgical aortic valve replacement in moderate risk patients implications for determination of equipoise in the transcatheter era. $J$ Thorac Cardiovasc Surg. 2014;147:127-32.

5. Charette K, Gerrah R, Quaegebeur J, Chen J, Riley D, Mongero L, et al. Single dose myocardial protection technique utilizing del Nido cardioplegia solution during congenital heart surgery procedures. Perfusion. 2012;27: 98-103.

6. Leon MB, Piazza N, Nikolsky E, Blackstone EH, Cutlip DE, Kappetein AP, et al. Standardized endpoint definitions for Transcatheter Aortic Valve Implantation clinical trials: a consensus report from the Valve Academic Research Consortium. J Am Coll Cardiol. 2011;57:253-69.

7. Eveborn GW, Schirmer H, Heggelund G, Lunde P, Rasmussen K. The evolving epidemiology of valvular aortic stenosis: the Tromso study. Heart. 2013;99: 396-400.

8. Bouma BJ, van Den Brink RB, van Der Meulen JH, Verheul HA, Cheriex EC, Hamer HP, et al. To operate or not on elderly patients with aortic stenosis: the decision and its consequences. Heart. 1999;82:143-8.

9. Charlson E, Legedza AT, Hamel MB. Decision-making and outcomes in severe symptomatic aortic stenosis. J Heart Valve Dis. 2006;15:312-21.

10. Assmann A, Minol JP, Mehdiani A, Akhyari P, Boeken U, Lichtenberg A. Cardiac surgery in nonagenarians: not only feasible, but also reasonable? Interact Cardiovasc Thorac Surg. 2013;17:340-3.

11. Edwards MB, Taylor KM. Outcomes in nonagenarians after heart valve replacement operation. Ann Thorac Surg. 2003;75:830-4.

12. Speziale G, Nasso G, Barattoni MC, Bonifazi R, Esposito G, Coppola R, et al. Operative and middle-term results of cardiac surgery in nonagenarians: a bridge toward routine practice. Circulation. 2010;121:208-13.

13. Blanche C, Matloff JM, Denton TA, Khan SS, DeRobertis MA, Nessim S, et al. Cardiac operations in patients 90 years of age and older. Ann Thorac Surg. 1997; 63:1685-90.

14. Samuels LE, Sharma S, Morris RJ, Kuretu ML, Grunewald KE, Strong MD III, et al. Cardiac surgery in nonagenarians. J Card Surg. 1996;11:121-7.

15. Easo J, Holzl PP, Horst M, Dikov V, Litmathe J, Dapunt O. Cardiac surgery in nonagenarians: pushing the boundary one further decade. Arch Gerontol Geriatr. 2011;53:229-32. 
16. Bacchetta MD, Ko W, Girardi LN, Mack CA, Krieger KH, Isom OW, et al. Outcomes of cardiac surgery in nonagenarians: a 10-year experience. Ann Thorac Surg. 2003; 75:1215-20.

17. Yamamoto M, Meguro K, Mouillet G, Bergoend E, Monin JL, Lim P, et al. Comparison of effectiveness and safety of transcatheter aortic valve implantation in patients aged $>/=90$ years versus $<90$ years. Am J Cardiol. 2012;110:1156-63.
18. Akin I, Kische S, Paranskaya L, Schneider H, Rehders TC, Turan GR, et al Morbidity and mortality of nonagenarians undergoing CoreValve implantation. BMC Cardiovasc Disord. 2012;12:80.

19. Green P, Woglom AE, Genereux P, Daneault B, Paradis JM, Schnell S, et al. The impact of frailty status on survival after transcatheter aortic valve replacement in older adults with severe aortic stenosis: a single-center experience. JACC Cardiovasc Interv. 2012;5:974-81. 


\section{APPENDIX E1. RISK FACTORS}

\section{Preoperative Chronic Medical Morbidity Risk Factors}

1. Myocardial infarction (MI): either clinical or electrocardiographic evidence was required for a diagnosis of previous MI. For patients having previously diagnosed MI, the duration since the most recent MI was noted. Transmural MI was diagnosed by the presence of new $\mathrm{Q}$ waves and an increase in creatine kinase, a heart musclespecific isoenzyme to a level indicating MI.

2. Hypertension: a diagnosis of hypertension was made if a blood pressure measurement $>140 / 90 \mathrm{~mm} \mathrm{Hg}$ was documented, a history of hypertension was present, or the patient was currently taking antihypertensive medication.

3. Congestive heart failure before this admission: if the patient has been treated for congestive heart failure before this admission but was not in congestive heart failure at level III or IV during this admission.

4. Stroke: a history of stroke, with or without residual defect.

5. Carotid/cerebrovascular disease: patients with $>50 \%$ cerebral artery obstruction, who have a history of a nonembolic stroke, or have required an operation for such disease. A history of bruits or transient ischemic attacks was not sufficient evidence for carotid/cerebrovascular disease.

6. Peripheral vascular disease: (1) patients with significant vascular disease in the aorta or iliac arteries or who had previously undergone surgery for such disease; (2) patients who had undergone previous revascularization of the femoropopliteal vessels, had absent or diminished pulses, those in whom an attempt to insert a balloonassist device had failed because of diminished femoral arteries, or those in whom an angiogram demonstrated a $>50 \%$ narrowing in a major femoral or popliteal vessel.

7. Chronic obstructive pulmonary disease: patients who were functionally disabled, required bronchodilator therapy, had a forced expiratory volume in 1 second of $<75 \%$ or $<1.25 \mathrm{~L}$, or had an oxygen pressure of $<60$ $\mathrm{mm} \mathrm{Hg}$ and a carbon dioxide pressure $>60 \mathrm{~mm} \mathrm{Hg}$ on room air.

8. Diabetes mellitus: patients with diabetes mellitus requiring either oral hypoglycemic agents or insulin.

9. Renal failure: patients with a preoperative creatinine $>2.0 \mathrm{~g} / \mathrm{dL}$ or patients with renal failure requiring chronic peritoneal or hemodialysis.

\section{Perioperative Risk Factors}

1. Preoperative intra-aortic balloon pump: if the patient arrived in the operating room with an intra-aortic balloon pump or required its insertion before the induction of anesthesia.

2. Previous percutaneous transluminal coronary angioplasty: if the patient had a percutaneous transluminal coronary angioplasty either during or before this admission. 